\title{
Development and Validation of a Cultural Dimensions Scale (CDS) and Its Application in an Iranian Context
}

\author{
Fahime Saboori \\ Ph.D. Candidate of TEFL, Ferdowsi University of Mashhad, Iran \\ Reza Pishghadam \\ Corresponding Author, Professor, Ferdowsi University of Mashhad, Iran \\ Email: pishghadam@um.ac.ir \\ Azar Hosseini Fatemi \\ Associate Professor, Ferdowsi University of Mashhad, Iran \\ Behzad Ghonsooli \\ Professor, Ferdowsi University of Mashhad, Iran
}

Doi:10.5901/mjss.2015.v6n4s3p367

\section{Abstract}

\begin{abstract}
The present study was conducted first, to construct and validate a Cultural Dimensions Scale (CDS) for the Iranian context. To this end, a scale was designed based on Hofstede's (2001) six-dimensional framework and was completed by 370 individuals. Its validity was then substantiated through Structural Equation Modeling (SEM). A second aim of this study was to reveal the norm of each cultural dimension for an important Iranian subculture which was achieved analyzing the data gathered from 1000 participants. Moreover, the relationship between gender and cultural dimensions was explored conducting a t-test. Also, a MANOVA was run to investigate the relationship between age and these dimensions. The results revealed a significant difference between men and women in the two dimensions of power distance and masculinity/femininity, and also, a significant difference between the three age groups in power distance, individualism/collectivism, and indulgence/restraint. In the end, the results were discussed and implications of the scale were presented.
\end{abstract}

Keywords: Validation, Cultural scale, Iran, Hofstede's cultural model/ dimensions

\section{Introduction}

There are undoubtedly numerous incentives to the study of culture; the most prominent one could be its determining role in setting the mindset of people. A pioneer in highlighting the effect of culture on cognition was Wundt (1916), the founder of experimental psychology, who proposed the idea that higher cognitive functions were affected by cultural practices, and that distinct cultures led to distinct cognitive processes (Norenzayan, Choi, \& Peng, 2007). A second important promoter of this idea was the influential Russian School of Vygotsky (1978) and Luria (1971). According to Vygotsky, a cultural context, as the historical pattern of tool-use of a group, hosts the development of human cognition. Different societies, due to divergence in their historical trajectories, offer different activities and tools which, in turn, afford different cognitive tendencies.

Culture opened its way in the field of psychology in the early $20^{\text {th }}$ century thanks to the works of scholars such as Sumner (1906) with his study of ethnocentrism and Wundt (1916) with the proposition of folk psychology (Keith, 2011). It, however, took almost 50 more years before culture turned into a key concept in psychology with the development of cross-cultural psychology in the second half of the $20^{\text {th }}$ century (Matsumoto \& Juang, 2008).

In the Handbook of Cross-Cultural Psychology, Triandis (1980) defined it as: "the systematic study of behavior and experience as it occurs in different cultures, is influenced by culture, or results in changes in existing cultures" (p. 1). One of the major approaches in cross-cultural psychology to studying the dynamic interdependence between the cultural and the psychological is the dimensional approach with its focus on quantifying differences (Markus \& Hamedani, 2007). 
Based on this approach, cultural differences (reflecting underlying basic value orientations, beliefs, and worldviews prevalent in a context) can be best captured by identifying and describing cultures according to where they fall along a series of dimensions.

This provides us with the possibility of measuring and comparing each context's distribution of behavior patterns, norms, attitudes, and personality variables (Triandis, 1989). This measurement or quantification is based on where the people engaging in a culture, on average, score along a series of dimensions, thereby creating a particular patterning.

Among different cultural models measuring culture based on certain criteria, that of Hofstede (1980) stands out as the most comprehensive and robust in terms of the number of national cultures samples (Smith, Dugan, \& Trompenaars, 1996), the most significant in studying cross-cultural values (Bhagat \& McQuaid, 1982), the most influential on the related literature (Chandy \& Williams, 1994; Sivakumar \& Nakata, 2001), and the most widely cited in existence (Bond, 2002). Hence, the present study has utilized this model for the study and measurement of an important Iranian subculture, namely, Khorasani culture.

\section{Theoretical Background}

The attempt to discover a comprehensive conceptual framework for understanding and measuring culture has for long occupied many social scientists. Not surprisingly, a review of the history of the conceptualization and measurement of culture endorses the existence of a wide range of scholarly opinions about which values, norms, and beliefs should be measured to represent the concept of culture and to form a basis for classifying cultures (Straub, Loch, Evaristo, Karahanna, \& Strite, 2002).

Controversy over this issue raged in the second half of the twentieth century (Hofstede, 2001). The most common dimension used for ordering societies has probably been their degree of economic evolution or modernity. A onedimensional ordering of societies from traditional to modern fitted well with the $19^{\text {th }}$ and $20^{\text {th }}$ century evolutionism that was characterized by a belief in progress (Mayr, 1982). Economic evolution is undoubtedly an important dimension that is inevitably reflected in societal values; however, it should not be allowed to suppress cultural variety in other respects (Hofstede, 1983).

There exist dimensions of culture unrelated to economic evolution which focus, instead, on shared values as the central feature and distinguishing characteristic of a culture (Hofstede, 1983). Examples of multidimensional theoretical models are those by Parsons and Shils (1951) with five pattern variables; by Kluckhohn and Strodtbeck (1961) with five value orientations; by Inkeles and Levinson (1969) with a set of standard analytic issues; by Douglas (1973) with two cosmologies; by Hall (1976) with two styles of communication; by Triandis (1994) with five cultural syndromes; and by Nisbett (2003) with two types of thinking. These multi- or bi-dimensional classifications have not been operationalized at the level of nations and, as a result, have not been sufficiently supported by empirical research at the level of modern societies. Hence, they just represent subjective reflective attempts to order a complex reality.

\subsection{Hofstede's Cultural Model}

Two features distinguish Hofstede's cultural approach from the previously mentioned multidimensional models: it is based on empirical research and at the level of national cultures (Hofstede, 2011). In this approach, culture is: "a collective programming of the mind which distinguishes the members of one group or category of people from others" (Hofstede $1980,25)$. Also, a dimension is defined as "an aspect of a culture that can be measured relative to other cultures" (p.7). A cultural model in this approach groups together the societal features which were empirically found to occur in combination along a dimension. Then a score is attributed to each country on each dimension and this way the differences among national cultures are measured.

Hofstede's theory of cultural dimensions highlights the impact of a society's culture on the values of its members, and how these values relate to behavior (Hofstede, 1980). His framework was developed using a large database collected by a multinational corporation (IBM) between 1967 and 1969 and again between 1971 and 1973. Based on a country level factor analysis, he classified the original 40 countries along four dimensions of national cultures.

The four dimensions were: Power Distance (PD), Individualism vs. Collectivism (IC), Masculinity vs. Femininity (MF), and Uncertainty Avoidance (UA). In the 1980s, a fifth dimension 'Long-term vs. Short-term Orientation' (LSO) was added to the four, on the basis of research by Canadian psychologist Michael Harris Bond centered in the Far East (Hofstede \& Bond, 1988). And, in the 2000s research by Bulgarian scholar Michael Minkov (2007) using data from the World Values Survey resulted in the addition of a sixth dimension, i.e. Indulgence vs. Restraint (IR). Table 1 presents definitions of each dimension. 
Table 1. Hofstede's cultural dimensions

\begin{tabular}{|c|l|}
\hline Dimension & Definition (Hofstede, Hofstede, \& Minkov, 2010) \\
\hline PD & $\begin{array}{l}\text {..the extent to which the less powerful members of institutions and organizations within a country expect and accept that power is } \\
\text { distributed unequally (p. 61) }\end{array}$ \\
\hline IC & $\begin{array}{l}\text { Individualism pertains to societies in which the ties between individuals are loose...Collectivism pertains to societies in which } \\
\text { people... are integrated into strong, cohesive in-groups (p.92). }\end{array}$ \\
\hline MF & $\begin{array}{l}\text { A society is called masculine when emotional gender roles are clearly distinct... A society is called feminine when emotional gender } \\
\text { roles overlap (p. 140). }\end{array}$ \\
\hline UA & $\ldots$..the extent to which the members of a culture feel threatened by ambiguous or unknown situations (p.191). \\
\hline LSO & $\begin{array}{l}\text { Long-term orientation stands for the fostering of virtues oriented toward future rewards...short-term orientation, stands for the } \\
\text { fostering of virtues related to the past and present (p. 239). }\end{array}$ \\
\hline IR & $\begin{array}{l}\text { Indulgence stands for a tendency to allow free gratification of natural human desires related to enjoying life and having fun. } \\
\text { Restraint, reflects a conviction that such gratification needs to be curbed and regulated by strict social norms ( } \mathrm{p} .281) .\end{array}$ \\
\hline
\end{tabular}

These dimensions are shortly explained in the following (Hofstede, 2011):

1. PD is related to the different solutions to the basic problem of human inequality. Although power and inequality are inevitable facts of any society, some are still more unequal than others. Accordingly, one way of distinguishing between nations can be based on how they tend to deal with these inequalities.

2. IC is related to the integration of individuals into primary groups. In individualistic cultures, everyone is expected to look after himself and his immediate family. In collectivist societies, however, people are integrated into cohesive in-groups, often extended families, that continue protecting them in exchange for unquestioning loyalty.

3. MF concerns the division of emotional roles between women and men. It opposes tough masculine to tender feminine societies. In masculine societies, men are supposed to be assertive, tough, and focused on material success, whereas women are supposed to be more modest, caring, and concerned with the quality of life. In feminine societies, both men and women are supposed to be modest, tender.

4. UA involves the level of stress in a society in the face of an unknown future. It deals with a society's tolerance for ambiguity and is not the same as risk avoidance; Uncertainty avoiding cultures try to minimize the possibility of unstructured situations by strict behavioral codes, laws and rules, disapproval of deviant opinions.

5. LSO is related to the choice of focus for people's efforts: the future or the present and past. Long-term oriented cultures show a pragmatic future-oriented perspective and underscore the values of thrift, perseverence, and adavptiveness. In short-term oriented cultures, on the other hand, a conventional historical short-term point of view prevails and immediate need gratification and respect for traditions are encouraged.

6. IR corresponds to the gratification versus control of basic human desires related to enjoying life. Its main correlates were found to be happiness, life control, and importance of leisure. The indulgence pole is characterized by a perception that one can act as one pleases and indulge in fun-related activities. At the restraint pole there is a perception that one's actions are restrained by social prohibitions and a feeling that enjoyment of leisurely activities are somewhat wrong and need to be regulated by strict social norms.

The publication of Culture's Consequences in 1980 provoked an influx of empirical studies based on the cultural theory introduced therein. They included replications (e.g. Pheng \& Yuquan, 2002), investigations of cultural change (e.g. Fernandez, Carlson, Stepina, \& Nicholson, 1997), cultural comparisons between countries (e.g. Wu, 2006), and correlations with other measures (e.g. Hoftede and McCrae, 2004). Moreover, practical applications of this cultural model were developed in a range of different fields including international management and marketing (Soares, Farhangmehr, \& Shoham, 2007), education (Sadeghi, Amani, Hanifepour, \& Mahmoudi, 2014), cross-cultural communication (Cronje, 2011), etc.

The abundance of such studies led to the emergence of a recent trend in the meta-analytic works reviewing the overall impact of Hofstede's cultural values framework on the literature. Examples of such meta-analyses are Kirkman, Lowe, and Gibson (2006) who qualitatively reviewed 180 studies published in business and psychology journals between 1980 and June 2002 in order to consolidate what is empirically verifiable about Hofstede's framework, as well as, Taras, Kirkman, and Steel (2010) who meta-analyzed the relationship between Hofstede's (1980) original 4 cultural value dimensions and a variety of organizationally relevant outcomes through a quantitative review of 598 studies.

\subsection{Iranian Culture in Hofstede's Framework}

Geert Hofstede's home website (www.geerthofstede.nl) offers the positions of more than 50 countries and regions on the 
cultural dimensions. These relative positions have been expressed in index scores which run from just above 0 to around 100 on each dimension. Fortunately, the Iranian culture has also been explored through the lens of the 6-D Model, presenting an overview of the deep drivers of this culture relative to other world cultures. The scores for the first four dimensions were collected between 1967 to 1973 while those of the next two dimensions were collected in the 1980s and 2000 s respectively.

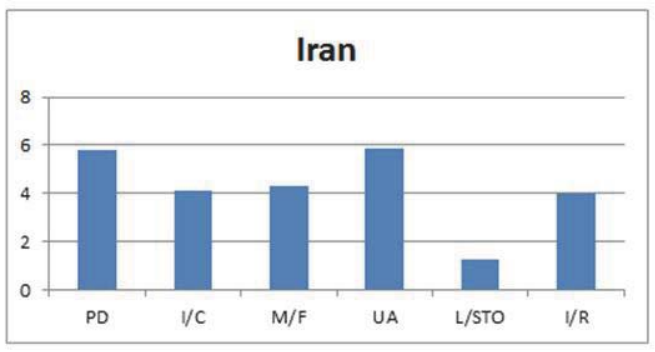

As evident in the chart, Iran scores highest on Uncertainty Avoidance (59) indicating its people's low tolerance of ambiguity and unstructured situations. On Power Distance, also, it has a high score (58) which means that people accept a hierarchical order and inequality in the society. Its score on Masculinity vs. Femininity dimension (43) represents Iran as a relatively feminine country in which the emotional and social role differentiation between genders is not high. In addition, based on its score on Individualism vs. Collectivism (41), Iran can be considered as a collectivist country in which people are integrated into strong, cohesive in-groups. On Indulgence vs. Restraint, this country scores 40 alluding to the fact that it has strict social norms which control the gratification of needs related to enjoying life and having fun. Finally, Iran scores lowest (13) on Short-term vs. Long-term Orientation. It implies this country's static orientation toward the present and the pastmanifested in valuing respect for tradition and personal steadiness and stability over flexibility and adaptability to different circumstances.

It should be noted that Iran as a relatively vast country is home to a wide assortment of ethnicities which, despite having historical commonalities, maintain distinct languages and religions (Dastmalchian, Javidan, \& Alam, 2001). Also, its Cultural Diversity Index (0.54) testifies to this country's high cultural heterogeneity (Fearon, 2003).

Khorasan is an important historical region located in the north east of Iran and has borders northward with Turkmenistan and eastward with Afghanistan (Mashhad University of Medical Sciences, 2015). It was the largest province of Iran until it was divided into three provinces in 2004: South Khorasan, North Khorasan, and Razavi Khorasan. Khorasan today is one of the major economic and social centers of Iran. Mashhad, as its capital city (now the capital of Razavi Khorasan), is the second most populous city in Iran. The city is however most well known and respected for housing the tomb of Imam Reza, the eighth Shia Imam. Historically speaking, Khorasan region has been the cradle of the Persian language and the civilization of eastern Iran. The major ethnic groups in this region are Persians, Kurds, Khorasani Turks, Turkmens, and Arabs. There is also an Afghan community in the province due to the influx of Afghan refugees coming from Afghanistan in recent years. Most of its people speak closely related dialects of Persian. Turkish and Kurdish are also spoken in parts of the region.

This multicultural region, however, has not been sufficiently studied and, to our knowledge, no systematic emic research has empirically investigated this and other Iranian subcultures, measuring and locating them based on cultural dimensions. Such scarcity drove the researchers first to devise an emic scale based on Hofstede's (2001) cultural model and next to examine and measure Khorasani culture, as an important Iranian subculture.

\subsection{Purpose of the Study}

This study pursued four goals: First, to construct and validate an emic Cultural Dimensions Scale (CDS) based on Hofstede (2001) six-dimensional framework to be used at the individual level of analysis; Second, to get the norm of each cultural dimension for the Khorasani culture; Third, to investigate the relationship between gender and cultural dimensions; Fourth, to investigate the relationship between age and cultural dimensions. 


\section{Methodology}

\subsection{Participants}

The present study was conducted on three groups of participants. The first group consisted of 12 people ( 5 men and 7 women) aging from 21 to 56 who took part in the pilot-testing phase of the study. The second group comprised 370 people taking part in the validation phase and the third group included 630 more people who completed the validated questionnaire. The participants were not chosen randomly but were selected based on accessibility and their willingness to cooperate. Nonetheless, measures were taken to collect data from a representative group of participants through including both genders at different ages with different educational levels living in different towns (including Mashhad, Neyshaboor, Chenaran, Sabzevar, etc.) in Khorasan, Iran. The following table depicts the demographic information of the 1000 participants.

Table 2. Participants' demographic information

\begin{tabular}{|c|c|c|c|c|c|c|c|c|c|c|}
\hline & \multicolumn{2}{|c|}{ Gender } & \multicolumn{3}{c|}{ Age } & \multicolumn{3}{c|}{ Education } & \multicolumn{2}{c|}{ Hometown } \\
\cline { 2 - 10 } & Male & Female & $18-25$ & $25-40$ & Above 40 & High school diploma & BS/ BA & Higher education & Mashhad & Other \\
\hline Participants & 443 & 557 & 535 & 356 & 109 & 507 & 377 & 116 & 659 & 341 \\
\hline
\end{tabular}

\subsection{Instrumentation}

The instrument used in this study was a Cultural Dimensions Scale (CDS) designed and validated by the researchers. The scale was to measure the six dimensions outlined in Hofstede's (2001) cultural model. The need for the development and application of the CDS, despite the availability of Hofstede's VSMs, is appreciated with regard to certain points. Firstly, it was designed to be used at the individual-level of analysis whereas the use of VSM would not be sensible "unless one has access to at least ten countries" (Hofstede et al., 2010, p. 49). Secondly, CDS is an emic scale particularly designed and appropriate for the Iranian context and hence is free of the ethnocentrism which, according to Kuhn (1970), is hidden in the employment of etic instruments. Thirdly, VSM was developed, in the first place, to be answered by IBM employees; hence, it mostly contains work-related questions and, unlike CDS, is not quite suitable for general use purpose.

CDS consisted of 26 four-point Likert scale items, ranging from (1) 'strongly agree' to (4) 'strongly disagree'. The scoring of some of the items needed to be reversed as the items included statements on both poles of each dimension. Four dimensions (PD, UA, LSO, IR) were measured by four items each and the two other dimensions (IC, MF) by five items each. The scale was designed in Persian, the mother tongue of the participants (See Appendix A for the English translation of the scale). Table 3 shows the numbers of the questions associating with each dimension.

Table 3. Questions measuring each dimension

\begin{tabular}{|c|c|}
\hline Dimension & Number of questions \\
\hline PD & $8,12,14,15$ \\
\hline IC & $3,9,13,16,17$ \\
\hline MF & $10,19,23,24,25$ \\
\hline UA & $2,5,6,26$ \\
\hline LSO & $1,4,7,11$ \\
\hline IR & $18,20,21,22$ \\
\hline
\end{tabular}

\subsection{Data Collection Procedures}

First, a CDS aimed at measuring the six cultural dimensions in the Iranian context was designed based on the related literature and in proper consultation with the pertinent experts. The outcome was a set of 26 items sharing 7 questions ( 2 , $7,20,21,22,23,24)$ with VSM 2013. It was then subject to the pilot-testing in order to disambiguate the items and ensure the content validity of the scale. Next, the revised version of the scale was administered to 370 participants and the data was used to substantiate the construct validity of the scale. Finally, an additional 630 participants completed the CDS. 


\subsection{Data analysis}

The data analysis entailed four phases. In the first phase, Structural Equation Modeling (SEM) via AMOS version 16 was utilized to substantiate the construct validity of the CDS. Next, the internal consistency of the whole scale as well as the reliability of each factor constructing the validated scale was assessed using the Cronbach Alpha reliability estimate. In the second phase, the descriptive statistics revealed the norm of each dimension for Khorasani culture. In the third phase, the t-test was run through SPSS version 16 to examine the relationship between gender and the cultural dimensions. And, in the last phase, Multiple Analysis of Variance (MANOVA) was conducted via SPSS to explore the relationship between age and cultural dimensions.

\section{Results}

\subsection{Validation of CDS}

Based on Hofstede's (2001) theory, a six-factor model of CDS with 26 items was specified (Figure 1). To confirm the factor structure of the proposed model, SEM was utilized. The goodness of fit measures in AMOS were used to examine the viability of the hypothesized model for the CDS. Chisquare/degree of freedom (X2/df), Goodness of Fit Index (GFI), Comparative Fit Index (CFI), and Root Mean-Square Error of Approximation (RMSEA) were the goodness of fit indices utilized in this study. To have an acceptable fit model, x2/df should be less than 3, AGFI, IFI, TLI, and CFI should be above .90, and RMSEA should be less than .08 (MacCallum, Browne, \& Sugawara, 1996). Results of the CFA indicated that all the goodness-of-fit indices were above the cutoff points (see Table 4). Therefore, the CFA confirmed the factor structure of CDS.

Table 4. Goodness-of-fit indices

\begin{tabular}{|c|c|c|c|c|c|c|}
\hline Fit Index & $\chi^{2} / d f$ & AGFI & IFI & TLI & CFI & RMSEA \\
\hline Acceptable Range & $<3$ & \multicolumn{5}{|c|}{$>90$} \\
\hline & 2.49 & 0.91 & 0.94 & 0.92 & 0.91 & 0.05 \\
\hline
\end{tabular}

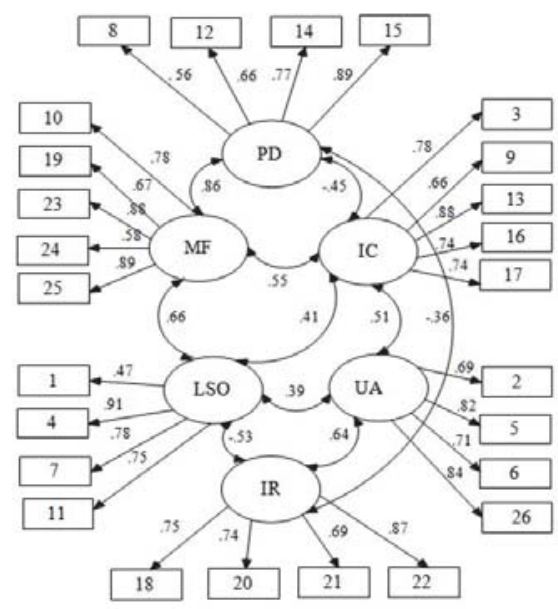

Figure 1. The result of CFA.

The Cronbach Alpha estimated the reliability of all the items as 0.79 . All of the six factors yielded good reliability estimates ranging from 0.68 to 0.81 . None of the items were removed after examining the outcome of the factor rotation. 


\subsection{Norms of the Dimensions}

Table 5 presents the descriptive statistics of the data collected by the CDS. A cursory inspection of the table reveals the norms of the cultural dimensions for the Khorasani culture. The highest mean belongs to IR (3.1289) whereas the lowest mean is that of IC (2.1483). The order of the dimensions from highest mean to lowest mean turned out to be:

IR $>$ PD $>$ UA $>$ MF $>$ LSO $>$ IC

Table 5. Descriptive statistics

\begin{tabular}{|c|c|c|c|c|c|c|}
\hline & PD & IC & MF & UA & LSO & IR \\
\hline N & 1000 & 1000 & 1000 & 1000 & 1000 & 1000 \\
Mean & 2.9929 & 2.1483 & 2.5506 & 2.7711 & 2.4461 & 3.1289 \\
Std. Deviation & .41750 & .41628 & .38545 & .45526 & .41460 & .49014 \\
\hline
\end{tabular}

\subsection{Gender and Cultural Dimensions}

T-test was conducted to find out whether there is a significant difference between men and women in the six cultural dimensions. The results of the t-test study are shown in the following table.

Table 6. Comparisons of mean scores of men and women regarding the cultural dimensions

\begin{tabular}{|c|c|c|c|c|c|c|c|c|c|c|c|c|}
\hline & \multicolumn{2}{|c|}{ PD } & \multicolumn{2}{|c|}{ IC } & \multicolumn{2}{|c|}{ MF } & \multicolumn{2}{|c|}{ UA } & \multicolumn{2}{|c|}{ LSO } & \multicolumn{2}{|c|}{ IR } \\
\hline Gender & $\frac{\frac{0}{N}}{\frac{N}{2}}$ & 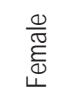 & $\frac{\frac{0}{\pi}}{2}$ & 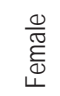 & $\frac{\frac{0}{\pi}}{2}$ & 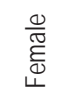 & $\frac{\frac{0}{0}}{\frac{\pi}{\Sigma}}$ & $\begin{array}{l}\frac{\Phi}{\widetilde{\sigma}} \\
\stackrel{\bar{\varpi}}{\Psi} \\
\end{array}$ & $\frac{\frac{0}{\pi N}}{\sum}$ & $\begin{array}{l}\frac{\Phi}{\widetilde{\Phi}} \\
\tilde{E}_{\mathbb{W}} \\
\Psi\end{array}$ & $\frac{\frac{0}{\pi}}{\sum \frac{\pi}{\Sigma}}$ & $\begin{array}{l}\frac{\Phi}{\widetilde{\varpi}} \\
\underset{\widetilde{E}}{\Psi} \\
\Psi\end{array}$ \\
\hline Mean & 3.08 & 2.91 & 2.15 & 2.14 & 2.58 & 2.52 & 2.74 & 2.79 & 2.45 & 2.43 & 3.13 & 3.12 \\
\hline S.D. & .39 & .41 & .42 & .40 & .40 & .36 & .47 & .44 & .41 & .41 & .48 & .49 \\
\hline T value & \multicolumn{2}{|c|}{5.43} & \multicolumn{2}{|c|}{.24} & \multicolumn{2}{|c|}{2.06} & \multicolumn{2}{|c|}{1.33} & \multicolumn{2}{|c|}{.47} & \multicolumn{2}{|c|}{.39} \\
\hline$P$ value & \multicolumn{2}{|c|}{.000} & \multicolumn{2}{|c|}{.808} & \multicolumn{2}{|c|}{.039} & \multicolumn{2}{|c|}{.182} & \multicolumn{2}{|c|}{.632} & \multicolumn{2}{|c|}{.693} \\
\hline
\end{tabular}

According to this table, the difference between men and women was significant in PD $(t=5.43, p<.05)$ and $M F(t=2.06, p$ $<.05)$. In both dimensions, men had higher scores than women. Regarding other dimensions, however, no significant difference was found between men and women.

\subsection{Age and Cultural Dimensions}

The descriptive statistics for the three age groups indicated that the highest mean was achieved by the first age range in IR (3.18) and the lowest mean belonged to the third age range in IC (2.00) (see Appendix B).

A MANOVA was performed in order to find out whether there is a significant difference among the three age groups in the six cultural dimensions. Table 7 presents the results of the multivariate tests. According to the table, the value of Wilks' Lambda is .951 $(p<.05)$ and this reveals a significant difference among the three age groups in the cultural dimensions.

Table 7. Results Multivariate Tests on the effect of age on the cultural dimensions

\begin{tabular}{|l|l|c|c|c|c|c|c|}
\hline \multicolumn{1}{|c|}{ Effect } & Value & $\mathrm{F}$ & Hypothesis df & Error df & Sig. & Partial Eta Squared \\
\hline \multirow{4}{*}{ Age } & Pillai's Trace & .056 & 3.356 & 12.000 & 1386.000 & .000 & .028 \\
& Wilks' Lambda & .944 & 3.368 & 12.000 & 1384.000 & .000 & .028 \\
\cline { 2 - 7 } & .059 & 3.380 & 12.000 & 1382.000 & .000 & .029 \\
& Hotelling's Trace & .059 & 5.406 & 6.000 & 993.000 & .000 & .045 \\
\hline
\end{tabular}


Furthermore, Table 8 demonstrates the dimensions in which this difference is significant. As the table suggests, there is a significant difference among the three age groups in PD ( $F=3.967, p<.05), I C(F=4.352, p<.05)$, and IR ( $F=6.327, p$ $<.05)$.

Table 8. Tests of Between-Subjects Effects

\begin{tabular}{|c|c|c|c|c|c|c|c|}
\hline Source & Dependent Variable & Type III Sum of Squares & df & Mean Square & $\mathrm{F}$ & Sig. & Partial Eta Squared \\
& $\mathrm{PD}$ & 1.371 & 2 & .686 & 3.967 & .019 & .011 \\
& $\mathrm{IC}$ & 1.494 & 2 & .747 & 4.352 & .013 & .012 \\
Age & $\mathrm{MF}$ & .673 & 2 & .337 & 2.274 & .104 & .006 \\
& $\mathrm{UA}$ & .019 & 2 & .010 & .046 & .955 & .000 \\
& LSO & .303 & 2 & .151 & .880 & .415 & .003 \\
& $\mathrm{IR}$ & 2.995 & 2 & 1.497 & 6.327 & .002 & .018 \\
\hline
\end{tabular}

Since the MANOVA demonstrated a significant difference among the three age groups in PD, IC, and IR, a post hoc Scheffe test was carried out for each of these dimensions to find out where exactly the difference lies. Table 9 presents the results of the Scheffe tests. According to the table, people in the first age range (18-25) had significantly lower scores in PD and IC dimensions than people in the third age range (above 40). That is to say, the oldest group of participants was significantly more individualist and had stronger belief in power distance than the youngest group. As for IR, people in the second age range (25-40) had significantly lower scores in IR and consequently led more restricted lives as compared to the people in the first age range (18-25).

Table 9. Results of Post Hoc Scheffe Test for the effect of age on PD, IC, and IR

\begin{tabular}{|c|c|c|c|c|c|c|c|}
\hline \multirow{2}{*}{ Age } & \multirow{2}{*}{$\mathrm{N}$} & \multicolumn{2}{|c|}{ Subset (PD) } & \multicolumn{2}{c|}{ Subset (IC) } & \multicolumn{2}{c|}{ Subset (IR) } \\
\cline { 3 - 8 } & & 1 & 2 & 1 & 2 & 1 & 2 \\
\hline $18-25$ & 535 & 2.9544 & & 2.0000 & & 3.1854 & \\
$25-40$ & 356 & 3.0381 & 3.0381 & 2.1313 & 2.1313 & & 3.1854 \\
$>40$ & 109 & & 3.0663 & & 2.1777 & 3.0969 & 3.0969 \\
Sig. & & .436 & .241 & .061 & .704 & .530 & .143 \\
\hline
\end{tabular}

\section{Discussion}

This study attempted, first to design and validate an emic scale for the measurement of the cultural dimensions in the Iranian context. To this end, a six-factor model of CDS with 26 items was designed based on Hofstede's (2001) theory. SEM was applied to substantiate the construct validity and reliability of the scale in the context of Iranian culture. The results of the goodness-of-fit indices showed a sufficient fit to the data confirming the factor structure of CDS. On such grounds, it can be claimed that CDS can be considered as an efficient scale for measuring the cultural dimensions in the Iranian context.

Taking such emic approach in cultural research is strongly recommended by Berry Poortinga, Segall, and Dasen (2002), being in line with his universalist orientation, and by Sternberg (2007), as promoted by his third model. They both maintain that the nature (underlying processes or dimensions) of a given construct is the same across cultures but since its manifestations differ from one culture to another its assessment calls for emic instruments.

The second goal of our study was to find out the norm of each cultural dimension for the Khorasani culture. According to the results, the order of the dimensions from the highest score to the lowest turned out to be: IR > PD > UA $>\mathrm{MF}>\mathrm{LSO}>\mathrm{IC}$. It can be inferred that in this culture the importance of enjoying life and having fun tend to be underscored, unequal distribution of power and hierarchical order are likely to be accepted and expected, unknown and ambiguous situations are to some extent unwelcomed, emotional gender roles are rather distinct, respect for past traditions and stability outweigh adaptiveness to new circumstances, and finally, the ties between individuals seem to be tight as they tend to be members of cohesive in-groups.

A point to be minded here is that any comparison between these findings and the ones obtained by Hofstede for Iran (available in his home website) needs to be made with care due to the following reasons: Firstly, our results characterize the culture of Khorasan, as an Iranian subculture, while those presented by Hofstede are claimed to define the culture of the whole country. Secondly, our study is an emic intracultural research whereas Hofstede's has been an 
etic inter-cultural research comparing different national cultures. And thirdly, the instruments utilized in the two studies were not the same.

Acknowledging these differences, still an important counterargument deserves particular attention. As mentioned earlier, Khorasan is one of the most important historical regions in Iran which has played a key role in the development of Iranian civilization (Mashhad University of Medical Sciences, 2015). Also, it is multicultural and home to the major Iranian ethnic groups. In addition, housing the tomb of the eighth Shia Imam has made it the religious capital of Iran and hence every year it receives millions of visitors from all over the country. All these shall pave the way for making the bold claim that Khorasan can be regarded as an acceptable representative for Iran and the norms obtained for this region may accordingly be generalized to the whole country. Adhering to this claim and considering the fact that the present study and that of Hofstede (1980) have both been founded on the same cultural theory (thus allowing for a rough comparison between the two) we discuss the obtained norms from the perspective of cultural change.

To reiterate, Hofstede's order of the dimensions from the highest mean to the lowest for the Iranian culture was: $\mathrm{UA}>\mathrm{PD}>\mathrm{MF}>\mathrm{IC}>\mathrm{IR}>\mathrm{LSO}$. When compared to our finding, the first striking difference seems to concern IR which has the first rank in this study and the fifth rank in Hofstede's. It follows that Iranians probably lead more indulgent lives as compared to the past. In addition, IC has the lowest score in this study while in Hofstede's results it occupies the third lowest rank. This change could imply a recent growth in collectivism in this society. Still another noteworthy change involves UA dimension as having the highest mean score in Hofstede's study and the third highest in the present research. It can thus be argued that Iranians have seemingly become more tolerant of unorthodox ideas and situations than they used to be. The remaining three dimensions do not have noticeable difference in the two orders as they either have the same position (PD) or have moved only one position back or forth (MF and LSO).

The third goal of this study was to investigate the relationship between gender and cultural dimensions. The results of the t-test revealed a significant difference between men and women in the two dimensions of PD and MF, in both of which, men had higher scores than women. For MF, not only is this difference not surprising but it is quite expected and alludes to the validity of the measurement of this dimension since, as the name suggests, it concerns masculine and feminine qualities and, according to Hofstede et al. (2010), is the only dimension on which men and women scored consistently differently, men having higher scores. As for PD, men's higher score denotes their higher support for inequalities and hierarchical order in the society. This seems to be justifiable by two reasons. First, as just mentioned, men tend to value masculine qualities such as competition, achievement, and being the winner / best in field more than do women. Clearly enough, these qualities necessitate and promote a hierarchical society. Second, one manifestation of such inequalities could be male domination whose prevalence in Iran, as Nazarian (2012) states, is indicated by this country's low score on GLOBE's gender egalitarianism. This male domination in Iranian society can be traced back to its religion and historical development (Javidan and Dastmalchian, 2003). Hence, it can be argued that men, as the benefactors of this inequality, show higher support for it.

The last goal of the present study was to investigate the relationship between age and cultural dimensions. Again, the MANOVA results showed a significant difference between the three age groups in PD, IC, and IR. The post hoc Scheffe test that followed revealed that young adults had significantly lower scores in PD and IC dimensions than older people and that the middle-aged people had significantly lower scores in IR as compared to the youth. The overall result of this part is in line with Harwood (2007) who argues for the particular importance of the same three cultural dimensions in the study of aging.

Also, one possible explanation for the PD results could be that in high PD societies age represents power and since everyone agrees to respect power elders have inherent status simply due to their age; therefore, the higher the power distance in a society, the more respect for and dependence on the seniors (Hofstede et al., 2010). Accordingly, the third group's higher scores could imply their expectation of such respect and dependence from others.

As for IC, our elder participants' higher scores appear to contradict Triandis (1995) who maintains that, in general, adults tend to become more collectivist as they age. Nonetheless, considering the close relationship between this dimension and independent/interdependent self construal (Hofstede et al., 2010), this finding is consistent with Guo, Schwartz, and McCabe' (2008) revealing that, in their two-factor model, older participants appeared unexpectedly higher on independence, compared to younger participants. In the same vein, our finding confirms Erikson's (1950) idea that humans seek self-realization in later stages of life.

Finally, with regard to $I R$, the results were indicative of the fact the second age group led more restrained lives as compared to the first age group. The first possible explanation that comes to mind is that adults under the age of 24 tend to have less major concerns, commitments, and responsibilities since it is normally in the second age range that they face such challenges as finding a job, getting married, becoming independent, etc. In addition, since IR is closely associated with subjective well-being or happiness (Hofstede et al., 2010), this finding can be claimed to be in line with a U-shaped 
theory of age and well-being. Such U-shaped pattern has been suggested and confirmed by many recent empirical studies (e.g. Van Landeghem, 2012; Weiss, King, Inoue-Murayama, Matsuzawa, \& Oswald, 2012; Blanchflower and Oswald, 2011; Lang, Llewellyn, Hubbard, Langa, \& Melzer, 2011) and maintains that well-being normally reaches its minimum in the 30s and that "the young and the old are happier than the middle-aged" (Frey \& Stutzer, 2002, p. 54).

At the end, the researchers acknowledge certain limitations of the present study. The first one is concerned with the number of variables taken into account. While four variables which have seemingly most influence on culture (gender, age, education, and hometown) were included, there are definitely other variables affecting culture which need to be also taken into account to increase the validity of the results. The second limitation deals with the number of the participants. Although it was tried to have a representative sample, a larger sample would be more representative and let the researcher draw more valid generalizations from the results.

\section{References}

Berry, J. W., Poortinga, Y. H., Segall, M. H., \& Dasen, P. R. (2002). Cross-cultural psychology: Research and applications (2nd ed.). New York: Cambridge University Press.

Bhagat, R. S., \& McQuaid, S. J. (1982). Role of Subjective Culture in Organizations: A review and directions for future research. Journal of Applied Psychology, 67(5), 653-85.

Blanchflower, D. \& Oswald, A. (2011). Antidepressants and age. IZA discussion paper No. 5785.

Bond, M. H. (2002). Reclaiming the individual from Hofstede's ecological analysis- A 20-year Odyssey: Comment on Oyserman et al. (2002). Psychological Bulletin, 128(1), 73-7.

Chandy, P. R., \& Williams, T. G. E. (1994). The impact of journals and authors on international business research: A citation analysis of JIBS articles. Journal of International Business Studies, 25(4), 715-28.

Cronje, J. C. (2011). Using Hofstede's cultural dimensions to interpret cross-cultural blended teaching and learning. Computers and Education, 56(3), 596-603.

Dastmalchian, A., Javidan, M., \& Alam, K. (2001). Effective leadership and culture in Iran. Applied Psychology: An International Review, 50(4), 532-558.

Erikson, E. H. (1950). Childhood and society. New York: Norton.

Douglas, M. (1973). Natural symbols: Explorations in cosmology. Harmondsworth, UK: Penguin.

Fearon, J. D. (2003). Ethnic and cultural diversity by country. Journal of Economic Growth, 8, 195-222.

Fernandez, D. R., Carlson, D. S., Stepina, L. P., \& Nicholson, J. D. (1997). Hofstede's country classification 25 years later. The Journal of Social Psychology, 137(1), 43-54.

Frey, B., \& Stutzer, A. (2002). Happiness and economics: How the economy and institutions affect well-being. New Jersey: Princeton University Press.

Guo, X., Schwartz, S. J., \& McCabe, B. (2008). Aging, gender, and self: Dimensionality and measurement invariance analysis on selfconstrual. Self and Identity, 7, 1-24.

Hall, E. T. (1976). Beyond culture. Garden City, NY: Anchor.

Harwood, J. (2007). Understanding communication and aging. CA: Sage.

Hofstede, G. (1980). Culture's consequences: International differences in work-related values. Beverly Hills, CA: Sage.

Hofstede, G. (1983). Dimensions of national cultures in fifty countries and three regions. In J. B. Deregowski, S. Dziurawiec, \& R. C. Annis, (Eds.), Expiscations in Cross-Cultural Psychology. Lisse, Neth.: Swets and Zeitlinger.

Hofstede, G. (1991). Cultures and organizations: Software of the mind. London, UK: McGraw-Hill.

Hofstede, G. (1997). The Archimedes effect. In M. H. Bond (Ed.), Working at the interface of cultures: 18 lives in social science (pp. 4761). London: Routledge.

Hofstede, G. (1998).Masculinity and femininity: The taboo dimensions of national cultures, Thousand Oaks, CA: Sage.

Hofstede, G. (2001). Culture's consequences: Comparing values, behaviors, institutions and organizations across nations. Thousand Oaks, CA: Sage.

Hofstede, G. (2011). Dimensionalizing cultures: The Hofstede model in context. Psychology and Culture, 2. Retrieved from http://scholarworks.gvsu.edu/orpc/vol2/iss1/8

Hofstede, G., \& Bond, M. H. (1988). The Confucius connection: From cultural roots to economic growth. Organizational Dynamics, 16, 421.

Hofstede, G., Hofstede, G. J., \& Minkov, M. (2010). Cultures and organizations: Software of the mind (3rd ed.). New York: McGraw-Hill.

Hofstede, G., \& McCrae, R. R. (2004). Culture and personality revisited: Linking traits and dimensions of culture. Cross-Cultural Research, 38, 52-88.

Inkeles, A., \& Levinson, D. J. (1969). National character: The study of modal personality and sociocultural systems. In G. Lindzey \& E. Aronson (Eds.), The Handbook of Social Psychology IV (pp. 418-506). New York: McGraw-Hill.

Javidan, M., \& Dastmalchian, A. (2003). Culture and leadership in Iran: The land of individual achievers, strong family ties, and powerful elite. Academy of Management Executive. 17(4), 127-142.

Keith, K. D. (2011). Introduction to cross-cultural psychology. In K. D. Keith (Ed.), Cross-Cultural Psychology Contemporary Themes and Perspectives (pp. 3-19). Oxford, UK: Wiley-Blackwell. 
Kirkman, B. L., Lowe, K. B., \& Gibson, C. B. (2006). A quarter century of Culture's Consequences: A review of empirical research incorporating Hofstede's cultural values framework. Journal of International Business Studies, 37, 285-320.

Kluckhohn, F. R., \& Strodtbeck, F. L. (1961). Variations in value orientations. Westport, CT: Greenwood Press.

Lang, I. A., Llewellyn, D. J., Hubbard, R. E., Langa, K. M., \& Melzer, D. (2011). Income and the midlife peak in common mental disorder prevalence. Psychological Medicine, 41(7), 1365-1372.

Luria, A. R. (1971). Towards the problem of the historical nature of psychological processes. International Journal of Psychology, 6, 259272.

MacCallum, R. C., Browne, M. W., \& Sugawara, H. M. (1996). Power analysis and determination of sample size for covariance structure modeling. Psychological Methods, 1(2), 130-149.

Markus, H. R., \& Hamedani, M. G. (2007). Sociocultural psychology: The dynamic interdependence among self systems and social systems. In S. Kitayama \& D. Cohen (Eds.), Handbook of cultural psychology (pp. 3-39). New York: Guilford Press.

Markus, H. R., \& Kitayama, S. (1991). Culture and the self: Implications for cognition, emotion, and motivation. Psychological Review, 98, 224-53.

Mashhad University of Medical Sciences. (2015). General information about Khorasan. Retrieved from http://www.mums.ac.ir/main/ en/khorasaninfo

Matsumoto, D., \& Juang, L. (2008). Culture and psychology (4th ed.). Belmont, CA: Thomson/Wadsworth.

Mayr, E. (1982).The growth of biological thought: Diversity, evolution, and inheritance. Cambridge, MA: Belknap Press of Harvard University Press.

Minkov, M. (2007). What makes us different and similar: A new interpretation of the world values survey and other cross-cultural data. Sofia, Bulgaria: KlasikaiStil.

Nazarian, A. (2012). Changes in scores of national culture dimensions in Iran by using individual level of measures. Brunel Business School-Doctoral Symposium.

Nisbett, R. E. (2003). The geography of thought: How Asians and Westerners think differently and why. New York: The Free Press.

Norenzayan, A., Choi, I., \& Peng, K. (2007). Perception and cognition. In S. Kitayama \& D. Cohen (Eds.), Handbook of cultural psychology (pp. 569-94). New York: Guilford.

Parsons, T., \& Shils, E. A. (1951). Toward a general theory of action. Cambridge, MA: Harvard University Press.

Pheng, L. S., \& Yuquan, S. (2002). An exploratory study of Hofstede's cross-cultural dimensions in construction projects. Manage Decis, 40(1), 7-16.

Sadeghi, K., Amani, J., Hanifepour, S., \& Mahmoudi, H. (2014). The impact of Iranian teachers cultural values on computer technology acceptance. The Turkish Online Journal of Educational Technology, 13(4), 124-136.

Soares, A. M., Farhangmehr, M., \& Shoham, A. (2007). Hofstede's dimensions of culture in international marketing studies. Journal of Business Research, 60, 277-284.

Sivakumar, K., \& Nakata, C. (2001). The stampede toward Hofstede's framework: Avoiding the sample design pit in cross-cultural research. Journal of International Business Studies, 32(3), 555-74.

Smith, P. B., Dugan, S., \& Trompenaars, F.(1996). National culture and the values of organizational employees: A dimensional analysis across 43 nations. Journal of Cross-Cultural Psychology, 27, 231-264.

Sternberg, R. J. (2007). Intelligence and culture. In S. Kitayama \& D. Cohen (Eds.), Handbook of Cultural Psychology (pp. 547-569). New York: Guilford Press.

Straub, D., Loch, K., Evaristo, R., Karahanna, E., \& Strite, M. (2002). Toward a theory-based measurement of culture. Journal of Global Information Management, 10 (1), 13-23.

Sumner, W. G. (1906). Folkways. New York: Ginn.

Tabachnick, B. G., \& Fidell, L. S. (2007). Using multivariate statistics. Boston: Pearson/Allyn \& Bacon.

Taras, V., Kirkman, B., \& Steel, P. (2010). Examining the impact of culture's consequences: A three-decade, multilevel, meta-analytic review of Hofstede's cultural value dimensions. Journal of Applied Psychology, 95, 405-439.

Triandis, H. C. (1980). Introduction. In H. C. Triandis \& W. W. Lambert (Eds.), Handbook of cross-cultural psychology (pp. 1-14). Boston: Allyn \& Bacon.

Triandis, H. C. (1989). The self and social behavior in differing cultural contexts. Psychological Review, 93,506-520.

Triandis, H. C. (1994). Culture and social behavior. New York: McGraw-Hill.

Triandis, H. C. (1995). Individualism and collectivism. Boulder, CO: Westmore.

Van Landeghem, B. (2012). A test for convexity of human well-being over the lifecycle: Longitudinal evidence from a 20-year panel. Journal of Economic Behavior and Organization, 7, 571-585.

Vygotsky, L. S. (1978). Mind in society: The development of higher psychological processes. Cambridge: Harvard University Press.

Weiss, A., King, J. E., Inoue-Murayama, M., Matsuzawa, T., \& Oswald. A. J. (2012). Evidence for a 'midlife crisis' in great apes consistent with the U-Shape in human well-being. Proceedings of the National Academy of Sciences, 19949-19952.

Wu, M. (2006). Hofstede's cultural dimensions 30 years later: A study of Taiwan and the United States. Intercultural Communication Studies, 15, 33-42.

Wundt, W. (1916). Elements of folk psychology: Outlines of a psychological history of the development of mankind. London: George Allen \& Unwin Macmillan. 


\section{Appendix A}

Cultural Dimensions Scale

\begin{tabular}{|c|c|c|c|c|}
\hline $\begin{array}{lll}\begin{array}{c}\text { Gender: Male } \\
\text { Educational degree: }\end{array} & \text { Female } & \begin{array}{c}\text { Age: } 18-25 \\
25-40\end{array} \\
\end{array}$ & Above 40 & metown: & & \\
\hline To what extent do you agree with the following statements? & Strongly agree & Agree & disagree & Strongly disagree \\
\hline 1. I maintain that traditions belong to the past and no longer need to be respected. & & & & \\
\hline 2. I often feel nervous or tense. & & & & \\
\hline 3. A psychologically healthy person is supposed to have no dependence on his/her family. & & & & \\
\hline 4. It is important to me to have unchangeable beliefs and behaviors that do not depend on shifting circumstances. & & & & \\
\hline $\begin{array}{l}\text { 5. For a good class, there is no need for structured learning situations with precise objectives, detailed assignments, } \\
\text { and strict timetables. }\end{array}$ & & & & \\
\hline 6. I prefer a predictable and routine life to a life with unpredictable events. & & & & \\
\hline 7. In my personal life. thrift (not spending more than needed) is important. & & & & \\
\hline 8. In my view, Children should be obedient toward and respect their parents. & & & & \\
\hline 9. For me, collective interests prevail over individual interests. & & & & \\
\hline 10. Women are better teachers for young children than are men. & & & & \\
\hline 11. Having long-term goals is of high importance to me, even at the price of present hardships. & & & & \\
\hline 12. The authority of a father (teacher) should not fade away through his friendly relationship with his child (students). & & & & \\
\hline 13. I believe marriage is a contract between families, not individuals. & & & & \\
\hline 14. I treat my teachers with respect, even outside the school or university. & & & & \\
\hline 15. My behavior toward others does not depend on their age or social status. & & & & \\
\hline 16. In my opinion, children had better live with their parents until they get married. & & & & \\
\hline 17. My family's opinion is very important to me in making an important decision in life. & & & & \\
\hline 18. In my life, having friends is not an important issue. & & & & \\
\hline 19. In the family, the standard pattern is that the father earns and the mother cares. & & & & \\
\hline 20. All in all, my state of health is good these days. & & & & \\
\hline 21. In my personal life, I keep some time free for fun. & & & & \\
\hline 22. Taking all things together, I would say that I am a happy person. & & & & \\
\hline 23. In my ideal job, the opportunity for advancement to higher-level jobs is more important than the job security. & & & & \\
\hline $\begin{array}{l}\text { 24. I care more about working with people who cooperate well with one another than about getting the recognition } \\
\text { one deserves for doing a good job. }\end{array}$ & & & & \\
\hline 25. In my ideal job, I prefer more leisure time over more money. & & & & \\
\hline 26. When coming across a novel and unknown situation, I am more prudent than curious. & & & & \\
\hline
\end{tabular}

\section{Appendix B}

Descriptive statistics for age \& cultural dimensions

\begin{tabular}{|c|c|c|c|c|}
\hline & Age & Mean & Std. Deviation & $\mathrm{N}$ \\
\hline \multirow{4}{*}{ PD } & $18-25$ & 2.9544 & .44008 & 535 \\
\hline & $25-40$ & 3.0381 & .38190 & 356 \\
\hline & $40-$ & 3.0663 & .38112 & 109 \\
\hline & Total & 2.9929 & .41750 & 1000 \\
\hline \multirow{4}{*}{ IC } & $18-25$ & 2.1777 & .42115 & 535 \\
\hline & $25-40$ & 2.1313 & .40656 & 356 \\
\hline & $40-$ & 2.0000 & .39791 & 109 \\
\hline & Total & 2.1483 & .41628 & 1000 \\
\hline \multirow{4}{*}{$\mathrm{MF}$} & $18-25$ & 2.5448 & .36033 & 535 \\
\hline & $25-40$ & 2.5781 & .43294 & 356 \\
\hline & $40-$ & 2.4531 & .29658 & 109 \\
\hline & Total & 2.5506 & .38545 & 1000 \\
\hline \multirow{4}{*}{ UA } & $18-25$ & 2.7747 & .44834 & 535 \\
\hline & $25-40$ & 2.7686 & .47008 & 356 \\
\hline & $40-$ & 2.7551 & .44044 & 109 \\
\hline & Total & 2.7711 & .45526 & 1000 \\
\hline \multirow{4}{*}{ LSO } & $18-25$ & 2.4278 & .41027 & 535 \\
\hline & $25-40$ & 2.4707 & .42717 & 356 \\
\hline & 40- & 2.4643 & .38188 & 109 \\
\hline & Total & 2.4461 & .41460 & 1000 \\
\hline \multirow{4}{*}{$\mathrm{IR}$} & $18-25$ & 3.1854 & .49708 & 535 \\
\hline & $25-40$ & 3.0479 & .47733 & 356 \\
\hline & $40-$ & 3.0969 & .44434 & 109 \\
\hline & Total & 3.1289 & .49014 & 1000 \\
\hline
\end{tabular}

